\title{
GAS SORPTION IN ENGINEERED CARbON NANOSPACES
}

\author{
Jacob Burress \\ Dr. Peter Pfeifer, Dissertation Supervisor
}

\begin{abstract}
Vehicular storage of gaseous fuels is a key enabling technology for the two pillars of a non-petroleum based transportation economy_natural-gas vehicles and hydrogen fuel cell vehicles. My research focuses on the development of nanoporous carbons as high-capacity storage materials for natural gas (methane) and molecular hydrogen. The carbons have surface areas of up to $3500 \mathrm{~m}^{2} / \mathrm{g}$, porosities of up to 0.8 . Extensive characterizations of the surface and pore structure of samples were performed. Characterizations include surface areas and pore-size distributions from nitrogen adsorption at $77 \mathrm{~K}$; pore-size distribution from methane adsorption at $293 \mathrm{~K}$; scanning and transmission electron microscopy; and chemical composition analysis.

In two case studies, it was found that $40 \%$ of all surface sites reside in pores of width $\sim 0.7 \mathrm{~nm}$ and binding energy $\sim 9 \mathrm{~kJ} / \mathrm{mol}$, and $60 \%$ of sites in pores of width $>1.0 \mathrm{~nm}$ and binding energy $\sim 5 \mathrm{~kJ} / \mathrm{mol}$. It was furthermore found that we can experimentally distinguish between the situation in which molecules do (mobile adsorption) or do not (localized adsorption) move parallel to the surface, how such lateral dynamics affects the hydrogen storage capacity, and how the two situations are controlled by the vibrational frequencies of adsorbed hydrogen molecules parallel and perpendicular to the surface: in the two case studies, adsorption is mobile at $293 \mathrm{~K}$, and localized at $77 \mathrm{~K}$. These findings make a strong case that, and how, hydrogen storage capacities in nanoporous carbons can be optimized by suitable engineering of the nanopore space.
\end{abstract}

